\title{
A Study of the Design and Evaluation of a Learning Object and Implications for Content Development
}

\section{Ferdinand Krauss University of Toronto, Canada}

\author{
Mohamed Ally \\ Athabasca University, Canada \\ mohameda@athabascau.ca
}

Abstract

This paper reports on a case study that examined the process of designing and evaluating a learning object to help students understand the therapeutic principles of drug administration. The challenges and issues associated with creating learning objects using interactive multimedia software will be described. The study had two broad objectives: (1) to analyze and document the process of designing a learning object and (2) to evaluate the outcome of applying these practices. To achieve its purpose, this illustrative case study examined the following areas, 1) theories of learning and cognition that influence the design of learning objects; and 2) instruments that can be used to assess the quality of the learning object and to provide designers with information for improving the learning object. The results from the evaluation revealed that the learning object was rated highly in the areas of content quality, learning goal alignment and motivation. Interaction/ usability and feedback/ adaptation were areas identified as needing improvement. The comments and ratings obtained in the student surveys provided the basis for the learning impact study and indicated that this learning object provides added value for the study of pharmacokinetics.

Keywords: learning objects, design, evaluation, elearning, web-based education, learning theory.

\section{Introduction}

Shaw (2002) stated that in developing learning resources, one should begin with a genuine instructional problem and should strive to achieve outcomes, which are not otherwise possible. Typically, pharmacokinetics (the therapeutic principles of drug administration) is one of the least well understood topics in the medical curriculum due to the complex nature of the subject as well as the methods for teaching it (Lawrence Spero, personal communication, January 23, 2003).

Currently, the primary method for teaching pharmacokinetics is via textbook with a minimum of lecture material. These static media do not adequately represent or visualize the relationships that exist between therapeutic principles and the parameters relating to the physical and pharmacol-

Material published as part of this journal, either on-line or in print, is copyrighted by the publisher of the Interdisciplinary Journal of Knowledge and Learning Objects. Permission to make digital or paper copy of part or all of these works for personal or classroom use is granted without fee provided that the copies are not made or distributed for profit or commercial advantage AND that copies 1) bear this notice in full and 2) give the full citation on the first page. It is permissible to abstract these works so long as credit is given. To copy in all other cases or to republish or to post on a server or to redistribute to lists requires specific permission and payment of a fee. Contact Publisher@ijklo.org to request redistribution permission. ogical properties of drugs. Printed text also does not convey the impact that a number of variables have on the overall effect of the drug and achievement of optimum therapeutic effect. These teaching methods reinforce the memorization of factual information and do not promote a deeper understanding or application of the principles involved.

A team consisting of an instructional designer, a programmer, a media de- 
signer, and a subject matter expert was used to develop the pharmacology learning object. A learning object is defined as, "any digital resource that can be used and re-used to achieve a specific learning outcome or outcomes” (Ally, 2004a, p. 3). Macromedia's Flash MX ${ }^{\mathrm{TM}}$ was used to design an interactive online module to help students learn about the major therapeutic principles of drug administration. The capabilities of ActionScript within Flash MX made it highly suitable for the design of this learning object. It allowed for the, "control of the program in a non-linear fashion, sophisticated interactivity, input tracking from the movie viewer, and the exchange and manipulation of data from external sources" (http://www.macromedia.com). Using the learning object, the student can practice the application of the principles by selecting different drugs from the database along with a variety of patient characteristics and routes of administration. The Flash learning object allows the students to manipulate the variables, and to see the corresponding results in a blood concentration time curve. This enables the students to develop a better understanding of these concepts as they are able to formulate and test hypothesis related to drug administration. Recognizing the conditions in which the principles apply will enable the student to predict and explain the effects of changing the variables. Demonstrations of the therapeutic principles are also provided. The learning object contains ten basic therapeutic principles (Melmon \& Morrelli, 1972) and fifteen drugs.

\section{Purpose of the Study}

The purpose of this study was to identify the challenges and issues that instructional designers face when designing learning objects and to evaluate the effectiveness of a learning object. The focus of the study was on the methodology for deciding on the scope and sequence of a learning object and on selecting the appropriate instructional strategies to achieve the desired outcomes. The Learning Object Review Instrument (LORI), version 1.4 developed by Belfer, Nesbit and Leacock (2002) was used to collect faculty's individual assessments of the quality of the pharmacology learning object and to determine areas for improvement.

\section{Research Questions}

To achieve its purpose the illustrative case study examined the following questions;

How do theories of learning and cognition influence the design of learning objects?

What instruments can be used to assess the quality of the learning object and to provide designers with information for improving it?

This case study has the potential to make an important contribution to the practice of instructional design by documenting the results of applying theoretical constructs to the development of an actual learning object. The results from this research could be used to inform educators about some of the considerations involved in designing a learning object. An examination of the process and instruments used for evaluation could provide valuable insights about methods that could be employed for the peer review of learning objects.

\section{Review of Related Literature}

This section includes an overview of the research and literature associated with the research questions stated in the introduction of this study. Literature that addresses learning theory and how these principles influence the design of learning objects is described. Secondly, an investigation of studies, which have identified instruments and processes for evaluating learning objects, is undertaken. 


\section{Learning Theory and Instructional Strategies for Learning Objects}

The behaviourist model of learning is based on Skinner's (1974) theory of stimulus and response. He observed the conditions under which an individual responded to a stimulus and suggested that reinforcement of a specific behaviour increased the probability that it would be repeated. This model is often associated with the process of writing learning objectives where the desired behaviour is stated in observable terms in order to describe what will be accepted as evidence that learners have acquired the knowledge and skills suggested by the goals. The learning activities are also sequenced in order to provide the reinforcement (feedback) necessary to promote the kind of behaviour that will lead to learning.

The broad framework of behaviourism is where the cognitivist notion of viewing knowledge as representations was derived (Hung, 2001). The focus shifted to the internal workings of the mind where learning was viewed as the process of manipulating these representations between shortterm, long-term and working memory (Ally, 2004b; Bannan-Ritland, Dabbagh, \& Murphy, 2000). In behaviourist theory, no connection is drawn between the experience of an individual and the abstract knowledge residing within their mind (Duffy \& Cunningham, 1996). The separation of learning strategies from content is based on the assumption that the rate of development for learners may differ, but that the process of development is similar for most people (Merrill, 1992; Smith \& Ragan, 2002). The implication is that, "...different learning outcomes require different cognitive processes and therefore different instructional strategies" (Bannan-Ritland et al., 2000, p. 15).

Abdelhamid (1999) studied how different cognitive strategies could be integrated with computerbased instruction to improve learning in medical students. His multi-dimensional learning model combines the generation effect with the spreading activation model and the use of illustrations in an effort to shift information from short-term memory to long-term memory. His research specifies three main principles that improve understanding and retrieval of information in students.

The generation effect. A learner that generates an item is more likely to recall the information than when it is merely read.

Spreading activation model. Stored information is more easily retrieved when it is remembered in the context of data, which is related and interconnected. Processing one piece of information leads to the activation of the other related items.

The use of pictures. Use of text and graphics can facilitate learning better than a verbal description.

In 1996, the School of Medicine and Health Science at the University of Auckland conducted a study on the effectiveness of the multi-dimensional learning model. The results indicated a significant increase in the academic performance of students that used the model, while no measurable improvement was recorded for the topics not covered by the theory (Abdelhamid, 1997, as cited in Abdelhamid, 1999, p. 4). In addition, the learners stated that they favoured this model over the traditional teaching methods. Abdelhamid (1999) extends the traditional cognitivist paradigm by making the student an active participant in a process where they are required to reflect upon or re-construct the information in an attempt to make sense of their environment. This signals a departure from the cognitivists' view of experience and knowledge as separate and conceptual (Hung, 2001). Instead, the focus revolves around the relationship between the context in which learning occurs and the knowledge being acquired, and represents what constructivists refer to as situated cognition. The spreading activation theory within the Multi-dimensional Learning Model (MDLM) shares similarities with Parallel Distributed Processing (PDP) theory as described by Bannan-Ritland et al. (2000). In both theories long-term memory is viewed as a dy- 
namic network of associated knowledge with numerous connections. The associations are a combination of knowledge and prior experience. To process the information is to stimulate the recall of the related knowledge simultaneously. The learner accommodates the new information by reconciling the 'cognitive dissonance' that results from the new knowledge. Deeper processing activates more associations resulting in meaningful learning and better storage (Ally, 2004b).

Bannan-Ritland et al. (2000) advocated the application of parallel distributed processing theory and constructivist principles to learning object systems. Students are encouraged to become the designers and use technology to generate representations of their knowledge and to analyze the ideas of other students. The authors go so far as to suggest that learners could tag, and manipulate and revise objects created by others. The focus here is on the process rather than the outcome, as in behaviourism. The role of the instructor would be to provide the process-based frameworks and guidance for integrating the various resources and approaches. A combination of these learning theories can be used to develop web-based instructional resources (Ally 2004b; Hung 2001).

\section{Evaluating Learning Objects}

Williams (2000) stressed the importance of making evaluation an integral part of the design process. He suggested the inclusion of formative and summative standards in order to improve the instructional process as well as the evaluation itself. His method combined Stufflebeam's (1971) CIPP (context, input, process, product) model with Patton's (1997) user-focused approach. Williams advocated a participant oriented model, one that would allow contributors to express their values and rationale for their evaluation criteria in cooperation with others. Participants would, "... learn of and acknowledge the importance of criteria associated with values held by other users with whom they are collaborating" (Williams, 2000 p 20).

This approach was adopted by Nesbit, Belfer, and Vargo (2002) in the design of their convergent participation model for the evaluation of learning objects. Their model proposed an evaluation panel drawn from different stakeholder groups and a two-cycle process, whereby participants would begin by evaluating the learning object independently and asynchronously. Subsequently, the panel would compare and provide rationales for their evaluations and have an opportunity to adjust their individual assessments. The two-stage cycle is facilitated by electronic communication tools and uses a Learning Object Review Instrument (LORI) developed by Belfer et al. (2002) that specifies the rating scale and criteria of evaluation. Subsequent research on the use of the LORI revealed that objects that were evaluated collaboratively led to greater inter-rater reliability as opposed to ones evaluated independently (Vargo, Nesbit, Belfer, \& Archambault, 2003). Anecdotal evidence from participants in the process also indicated that it was an excellent way for them to increase their understanding of learning object design.

Two recent studies (Nyhof-Young, Walsh, \& Stewart, 2002; Rose, 2003) have examined evaluation strategies in order to determine the impact on learning for students using digital resources. In the first study, a variety of methods were used to evaluate the extent to which and under what circumstances a functional neuroanatomy CD-ROM would facilitate learning in different groups of medical students. The methods included; 'think aloud' sessions, focus groups, a semi-structured questionnaire, user session log file analysis and speed of information retrieval tests. The study concluded that the CD-ROM significantly increased the students' ability to retrieve accurate neuroanatomical information and revealed their perceptions of the characteristics of quality digital learning resources (Nyhof-Young et al., 2002).

In 2003, Rose undertook a 'learning impact study lite' of eight learning objects submitted to the Cooperative Learning Object Exchange (CLOE, http://cloe.on.ca). Limited data collection methods and small sample sizes were used to obtain formative data relating to the reusability and potential improvements of the learning objects. A questionnaire was used to measure the learning 
impact on students from each of the institutions where the learning object originated. The surveys used four sub-scales; Learning Value, Value added by the Learning Object, Usability of Learning Object and Usability of technology. Additionally, self reports were used to collect the experiences and views of instructional designers and faculty involved in the development of the learning objects. They also included their assessment regarding the re-usability of the learning objects and the work required to revise it for their instructional purposes.

\section{Methodology}

This section provides a background to the study, the applied research design, a description of the participants and an explanation of the data collection process and analysis. The purpose of this study was to contribute to a better understanding of how instructional designers make decisions about developing learning objects. The examination was expected to reveal the kinds of decisions that instructional designers make when engaged in this type of activity. The study had two broad objectives: to document the process of designing a learning object and to illustrate the outcome of applying these practices. To achieve its purpose the illustrative case study examined the following questions:

How do theories of learning and cognition influence the design of learning objects?

What instruments can be used to assess the quality of the learning object and to provide designers with information for improving it?

A number of research strategies were applied in order to answer these questions. Current literature on learning theory and cognition were employed to design appropriate instructional strategies to be used with the learning object. Faculty and students were asked to participate in the evaluation of the learning object using a rating instrument and survey questionnaires. Theories of learning and cognition were applied to the design of the pharmacology learning object in order to create a student and instructor guide containing potential instructional strategies to be used with the resource. An analysis of how these theories influenced the layout, presentation and sequencing of information was also completed.

Three main strategies were used to assess the quality of the learning object and to collect formative data for improving the resource. Early in the design stage the instructional designer conducted usability testing with a third year pharmacy student to obtain feedback on design and navigation issues. This informal meeting was conducted as a 'think-aloud session' where the instructional designer recorded the reflections of the student as she interacted with the learning object. Secondly, peer reviewers were asked to evaluate the quality of the learning object using an established rating instrument and to provide feedback for improvement using an instructor survey. Thirdly, questionnaires were distributed to students in order to carry out a learning impact study based on their use of the learning object.

\section{Participants}

The initial reviewer involved in the think-aloud session was selected because of her ability to provide feedback from the perspective of being a former pharmacology student and as a current pharmacy student (both were identified as target audiences for the learning object). Health science faculty and students from two separate institutions participated in the formal evaluation of the learning object. The institutions were members of the CLOE consortium and were committed to collaborating in such activities. None of the participants were required to have experience with learning objects or online resources. The only criterion for selection was that they indicated an interest in potentially using the learning object for instruction or studying. 


\section{Instruments}

The Learning Object Review Instrument (LORI), version 1.4 developed by Belfer et al. (2002) was used to collect faculty's individual assessments of the quality of the pharmacology learning object and to ensure that a consistent evaluation criteria was used by all participants. Faculty were asked to assess the learning object in the following areas using a five point rating scale ranging from low to high and to provide a rationale for their score (see Table 1).

Table 1. Learning Object Review Instrument Evaluation Criteria

1. Content Quality: Veracity, accuracy, balanced presentation of ideas, and appropriate level of detail.

2. Learning Goal Alignment: Alignment among learning goals, activities, assessments, and learner characteristics.

3. Feedback and Adaptation: Adaptive content or feedback driven by differential learner input or learner modeling.

4. Motivation: Ability to motivate, and stimulate the interest of an identified population of learners.

5. Presentation Design: Design of visual and auditory information for enhanced learning and efficient mental processing.

6. Interaction Usability: Ease of navigation, predictability of the user interface, and the quality of the user interface help features.

7. Reusability: Ability to port between different courses or learning contexts without modification.

8. *Value of accompanying instructor guide: ability of resource to enhance instructional methodology.

Source: Adapted from Belfer, et al. (2002)

*(The original items in the LORI that dealt with accessibility and standards compliance were replaced with the category in item 8 because the participants lacked the necessary knowledge to provide an assessment in both of those areas).

Slight modifications were made to the instructor and student surveys developed by Leeder (2003) of the Universities' Collaboration in eLearning. These tools were used to provide faculty with an opportunity to suggest modifications for improvement and to provide evidence that the use of the learning object positively impacted student learning of pharmacokinetics.

The instructor survey was used to obtain specific feedback regarding revisions that were perceived necessary in order to improve the quality of the learning object and to make it more reusable across disciplines. The following information was sought:

additional strategies that could be included in the instructional guides to enhancing the learning of therapeutic principles,

how to improve the demonstrations of the therapeutic principles.

Questionnaires were distributed to students in order to carry out a learning impact study based on their use of the learning object. A section for open-ended comments was included in the survey so that students could qualify any of their ratings with a statement. 


\section{Data Collection}

The evaluation of the pharmacology learning object and the learning impact study took place over a period of two weeks and was completed individually. The LORI was not used in combination with the convergent participation model for the evaluation of learning objects as proposed by Nesbit et al. (2002). The goal of using the instrument was not to increase inter-rater reliability and the process of a collaborative evaluation would have been difficult to manage and would have required more time of the evaluators. The website location of the learning object (http://icarus.med.utoronto.ca/lo) along with the following electronic documents were sent via email to aid participants in the evaluation process; description of LORI, rating sheet, instructor and student surveys, and learning guides for instructors and students. The responses to the questions were entered into the electronic documents, re-saved and returned to the authors via email.

\section{Data Analysis}

The observations that were recorded as part of the think-aloud session were analyzed to determine the feedback that would have the greatest impact on the design of the learning object. A quantitative analysis of the LORI scoring sheets that were completed by instructors was not done as the small number of faculty available to complete the evaluation would have produced statistically insignificant results. Rather, their ratings and rationale for scoring were recorded on the LORI scoring sheet to determine the categories where the learning object received its highest and lowest ratings.

The student questionnaire items were combined into four sub-scales: Learning Value; Value Added by the Learning Object; Usability of Learning Object; Usability of Technology (Rose, 2003). This allowed the presentation of student perceptions related to these aspects of the learning object. The answers to the open-ended questions on the instructor and student surveys were aggregated and ordered by frequency.

\section{Results}

\section{Learning Theory}

This section will demonstrate the application of learning theories to the design of the pharmacology learning object and the instructional strategies that were prescribed as a result. As BannanRitland et al. (2000) state, "learning object systems present yet another technology-based instructional delivery environment with exciting features and attributes that can empower learner-driven experiences and promote cognitive processing if pedagogical considerations are taken into account in their development and evolution" (p. 1).

The following learning objectives were identified for the pharmacology learning object.

The learner will be able to list and describe the major therapeutic principles of drug administration.

Given a demonstration of a therapeutic principle the learner will be able to identify and replicate the relationship between the concepts (i.e. absorption, distribution, metabolism, and excretion of drugs) that underlie the principle.

The learner will be able to identify the relevant principles that describe the magnitude and direction of change plotted in the blood concentration time curve as well as a visual representation of the area under the curve (AUC). 
By manipulating the patient variables, routes of administration and drug dosage the learner will be able to correctly explain, predict and control the effect of these changes on the patient.

Explicitly stating the learning objectives made it easier for the instructional designer to determine the type of learning outcome the goal represented and to prescribe the necessary strategy. The first three learning objectives above corresponded to an expository approach in which the "Basic Principles" tab was designed to demonstrate each principle graphically. In this approach the principles were presented and demonstrated, and then learners had an opportunity to practice applying them.

\section{Demonstration phase}

The steps below correspond to Figure 1 of the Basic Principles Tab.

1. In the "Basic Principles" tab each principle is stated and then presented visually. At this point it is useful for learners to practice stating the principle.

2. The demonstrations illustrate how these rules can be used to explain, control and predict the effects of drug administration. The results are plotted in the "Blood Concentration Time Curve".

3. The description that accompanies the animation explains the 'whys' of the principle.

4. The demonstrations refer to concepts (absorption, distribution, metabolism, and excretion of drugs) and terminology (physiology/ anatomy) that the learner may have previously acquired. During this phase, learners retrieve this prior knowledge in order to understand the principles.

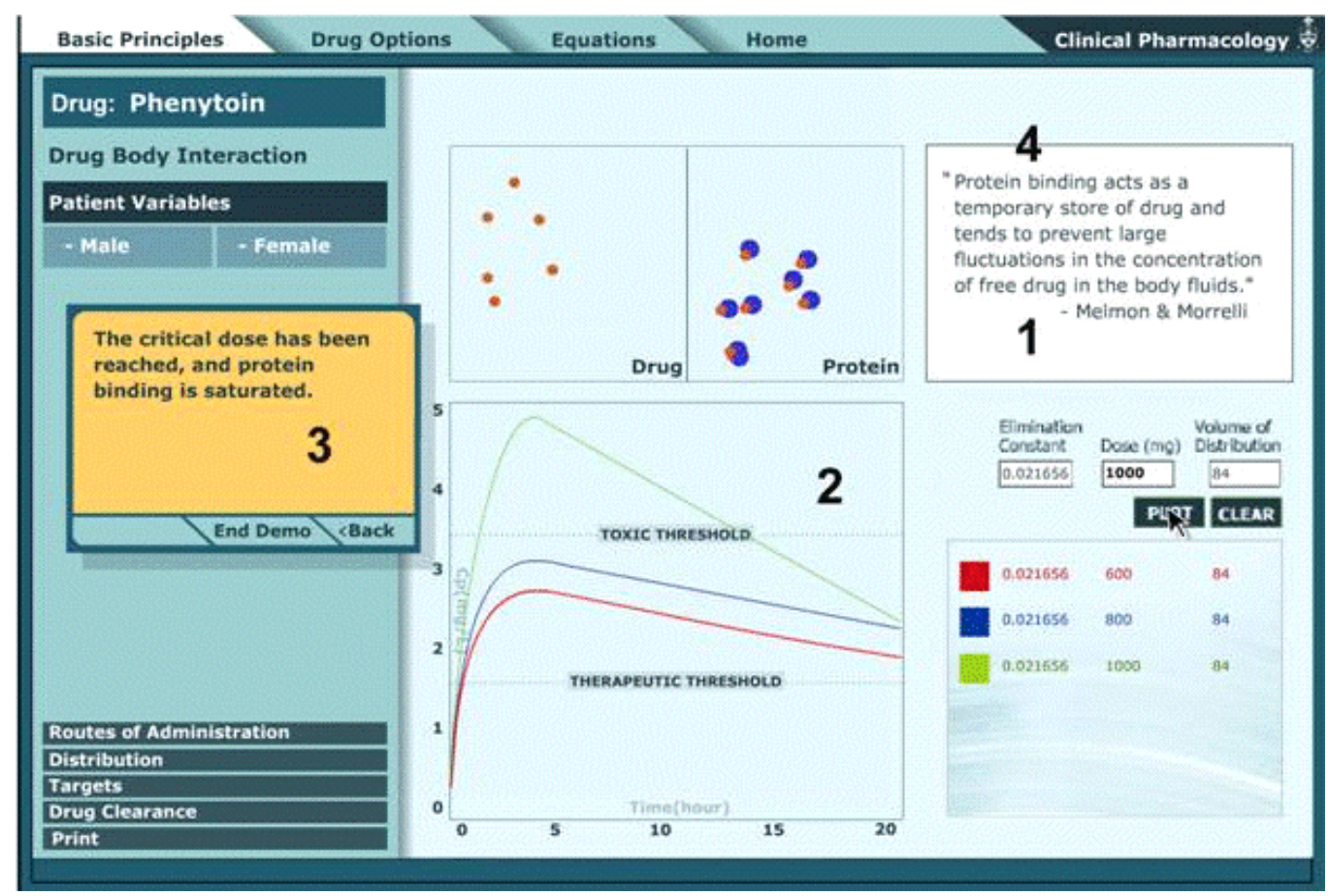

Figure 1: Basic Principles Tab 


\section{Practice phase}

Once the learners have completed viewing the demonstrations of each principle they can rehearse identifying circumstances in which the principle is applied. The practice of retrieving this information will help the learner to retain the information in long term memory.

1. Using the "Drug Options" tab the student can practice replicating the basic principles by selecting a range of patient variables, routes of administration and drug dosages. The learner begins by stating the principle they want to replicate.

2. As the learners experience the applications of the principles they are encouraged to focus their attention on the direction and magnitude of change that occurs in the 'blood concentration time curve' (see arrow in Figure 2) or area under curve (AUC) as a result of a variable being changed. Unless attention is given to this information it will be lost from memory.

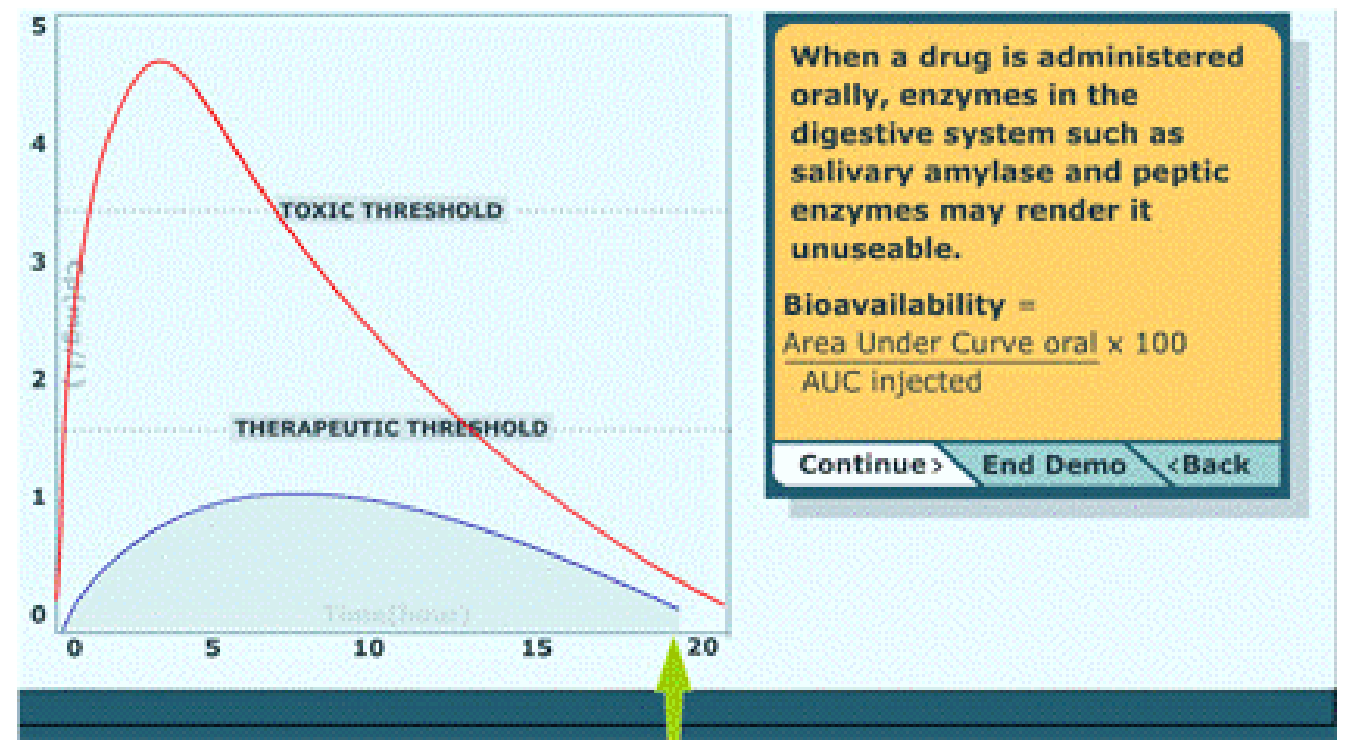

Figure 2: Blood Concentration Time Curve

3. After sufficient practice the student will be able to identify the features of the situation that suggest a particular principle is being applied and become proficient in correctly explaining, predicting and controlling the effect of these changes on the patient. In order to shift the principle that is being learned from short-term memory to long-term memory the steps that were taken to generate the principle must be rehearsed within 30 seconds (see Figure 3).

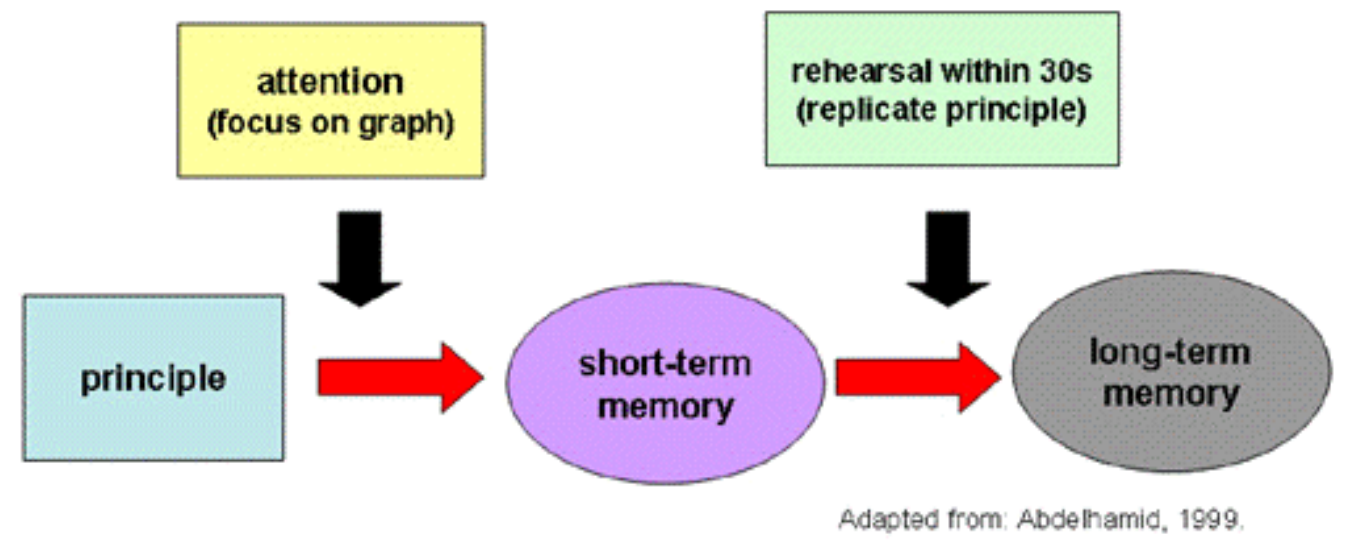

Figure 3: Separate Store Model 
The fourth learning objective corresponds to an inquiry approach in which the learner uses trial and error to learn about the basic therapeutic principles. Student can randomly select a range of patient variables, routes of administration and drug dosages and try to induce the principle that applies to that situation.

\section{Inquiry approach}

Using the 'drug options' tab the student can randomly select a range of patient variables, routes of administration and drug dosages and try to induce the principle, which applies to that situation.

In order to apply a principle the student engages in the following steps:

Determine which concepts or variables are involved. Using trial and error, the student can randomly select a range of patient variables, routes of administration and drug dosages. In Figure 4 the drug dosage has been increased from 10 to $20 \mathrm{mg}$ (type 20 in the dose box and click on plot). The area underneath the blue curve and above the red curve represents the magnitude of the change caused by the increase in the dosage.

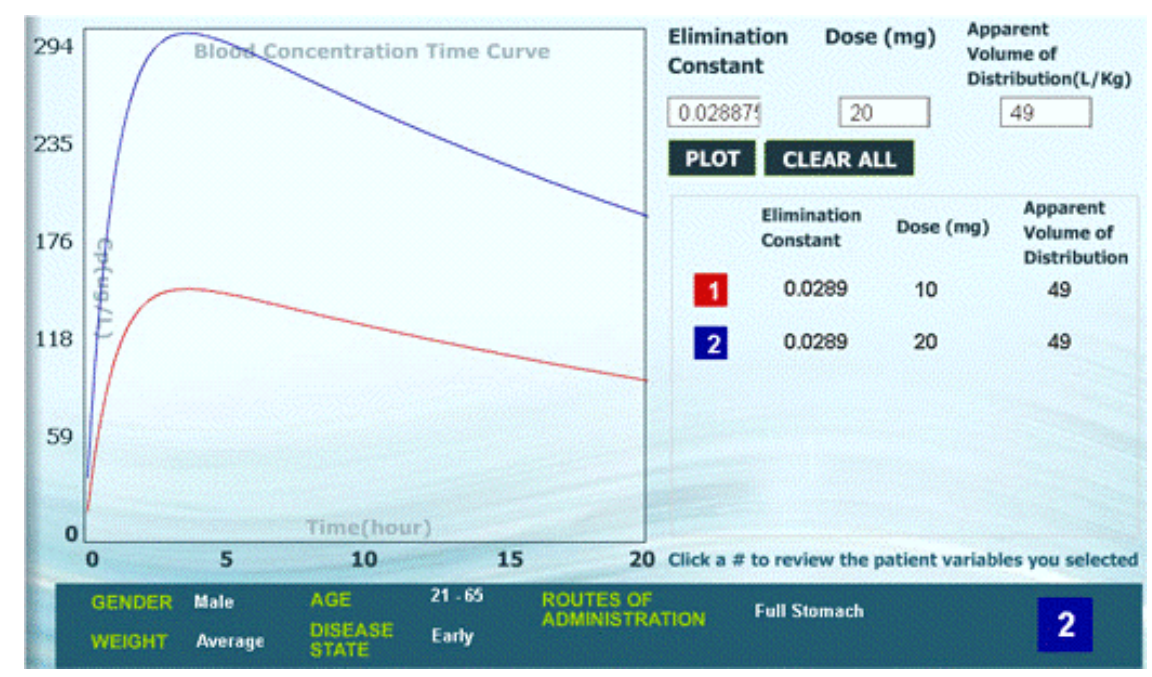

Figure 4: Drug Dosage

Try to determine the principle that explains the relationship between the concepts that apply to the variables you have chosen. Describe the effects that this might have on the patient.

Recall the principle. If it is necessary the learner can return to the "Basic Principles" tab.

Determine which concept or variable has changed and the direction or magnitude of its change (i.e. increasing dose by $10 \mathrm{mg}$ ). By clicking the coloured numbers, which appear next to the charted data, the learner can review the patient variables that were selected for that example.

Determine which concept or variable has been affected (i.e. protein binding when phenytoin dose is increased).

Then determine the magnitude and direction of the effect (AUC) on the affected concept or variable.

Confirm that the value is reasonable. Practice determining whether or not the principle has been correctly applied. Source: adapted from Smith and Ragan (1999) 


\section{Evaluation}

The goal of the design team was to produce an engaging, factually accurate, pedagogically sound, effective and reusable learning object. Therefore, the focus of the learning object evaluation was to obtain an indication of the quality of the resource as well as to collect formative data that could improve its design.

\section{Think-aloud session with student}

Early in the design process an informal 'think-aloud session' was conducted with a Pharmacy student so that the instructional designer could record the observations of the student as she interacted with the learning object. As a result of this session specific changes were made to the learning object. The most notable changes are recorded below.

Student observation. It did not occur to the student that she could interact with the learning object to change the volume of distribution and dosage to affect the blood concentration time curve.

Subsequent design change. An animation showing how to change the volume of distribution and dosage to affect the blood concentration time curve was included in the demonstration of a basic principle.

Student observation. What were the patient variables selected for the first plotting of the graph?

Subsequent design change. By clicking the coloured numbers, which appear next to the charted data, the learner can review the patient variables that were selected for that example.

Student observation. Elimination constant means little without the equation.

Subsequent design change. An equation tab was created with an explanation of the variables.

Student observation. Draw attention to changes in patient variables, routes of administration, etc.

Subsequent design change. Text descriptions highlighted in color were included in the demonstrations of the principles subsequent to the changes to explain what had changed and the resulting effect.

The interview was also useful for obtaining information about some of the instructional methods currently employed to teach pharmacokinetics. The student commented that a fairly narrow range of principles were taught and that the structured experiments provided little opportunity for heuristic approaches (unlike the learning object). She also stated that the learning object aided in the conceptualization of principles and that it could be effectively applied to case studies where learners could discuss the effects of the drugs on the patient variables that were viewed in the blood concentration time curve graph.

\section{Learning Object Quality - Instructor Ratings}

Each of the evaluators was assigned a code (i.e. E1). The rationale for their ratings and the corresponding scores were recorded in Appendix A. The results indicate that the learning object scored high in the categories of content quality, motivation and instructor/ student guides. It also rated very good to high in learning goal alignment, presentation design and reusability. Interaction/ usability and feedback/ adaptation received the lowest scores. 


\section{Instructor survey}

The instructor survey was used to obtain specific feedback regarding revisions that were perceived necessary in order to improve the quality of the learning object and to make it more reusable across disciplines. In addition to minor comments about enhancing the labelling of legends and the use of color there were some important suggested modifications for making the learning object more reusable.

Will this LO be useful and effective for your own teaching and learning needs? If not, how could it be improved?

"I believe it could be used for some applications in my teaching in immunology and microbiology, but that some additional support material might be required."

Will this LO be reusable across disciplines? If not, how could it be made more reusable?

"Yes, it should be reusable - but this could require additional resources, depending on the background of the audience. An extra module containing support material about the drugs chosen would be useful for student support. This might also be useful for instructors without much background in pharmacology, especially to allow for connections to be made between drugs that might be of interest for teaching examples in another discipline, but were not used as specific examples in the $\mathrm{LO}$ - for example, cyclosporin for an immunology course."

\section{Student survey}

The results of the 'learning impact lite' studies provided important evaluation data related to the students' use of the learning object. Student Questionnaire results appear in Appendix B. These results show that $75.7 \%$ and $77.5 \%$ of the possible responses within the Learning Value subscale and the Value Added subscales, respectively, were in the Agree and Strongly Agree categories. The responses for Usability of the Learning Objects and Usability of the Technology were in the Agree and Strongly Agree categories $80.0 \%$ and $92.0 \%$ of the time, respectively.

Student comments. The responses to the following questions that expressed the most common themes were recorded.

What did you like about this LO?

"I like the use of animations. I am a visual learner so any type of diagram is helpful, but animations are sort of novel and made the module more interesting."

"I liked the way it was broken down into the simplest components so you could figure it out yourself even if you still weren't sure about the material. Also, the fact that it is always there and you don't have to go out and get a CD."

"The interactive process and the use of the graphs related to drug effect on the body."

How could this LO be improved?

"Need to make output continue to relate to variables chosen by the learner. Should label diagrams a bit better for use beyond the demos. Should be able to have 'type of drug' selection as well, not just specific drugs."

"Sounds, more use of animation to support use of formulas. Narration. Glossary. Drug dictionary to describe what it is for."

Please use this space for any further comments you'd like to make about the LO including clarification of any of your responses. 
"I would not prefer just a lecture on the topic. I feel that a lecture and a seminar using the LO would work well together."

"The equations page was kind of useless for a basic knowledge of pharmacology. It doesn't tell you what it's for and how it is tied in."

"I found that the LO improved understanding of pharmacokinetic principles."

\section{Discussion}

This section will present a summary of the results for the illustrative case study. They have been organized in the following manner. First, the theories that influenced the design of the instructional strategies will be examined. The subsequent section will look at the tools and process that were used to evaluate the learning object and the results of the findings.

\section{Learning Theory}

Shaw (2002) and Wiley (2000) examined components of successful performance to determine how a strategy works in relation to what is known about dynamics of learning in a particular domain. Smith and Ragan (1999) stated that it is important for authors writing about instructional design to articulate the values embodied in their educational philosophy and that they be based upon theories that have been substantiated by empirical research.

For the development of the pharmacology learning object a pragmatic approach was taken and a combination of learning theories were used, including elements of; behaviourism, generative and cognitive theories and constructivism. Smith and Ragan (1999) defined pragmatists as those individuals that are inclined to believe that although knowledge is attained through experience (objectivist), it is personally interpreted through reason and is tentative in nature. Knowledge within a discipline is a result of negotiation between experts that work towards a universal understanding of experience or "truth for now". Knowledge continues to grow as a result of testing what is accepted as truth and revising it as subsequent experiences reveal new insights (constructivist).

The authors agree with a number of other writers (Ally, 2004b; Duffy \& Cunningham, 1996; Smith \& Ragan, 1999) that there is limited value in asserting which theory of learning is better. Rather, the adoption of a combination of instructional approaches was based on the belief that different instructional conditions are necessary to effectively promote a given type of learned performance. The role of the instructional designer is to prescribe an appropriate strategy and context for learning based on the learning objectives.

The design of the learning object adopted the following behaviourist attributes. Learning goals were explicitly stated in observable terms in order for the learners to establish whether or not they had achieved the desired outcomes. The learning object was sequenced so that students could progress from knowledge acquisition (using basic principles tab to view demonstrations of the principles) to higher order domains (application of principles using the drug options tab). Feedback was presented to students in the form of a graph, which plotted the blood concentration time curve, and served as feedback to indicate if the student had applied the theory correctly.

Characteristics of generative learning theory were also evident in the design of the learning object. The learner was actively engaged and assumed primary responsibility for processing the information. The pharmacology learning object required the students to interact with the resource to create an outcome (graph on blood concentration time curve). As a result they were more likely to retrieve the relevant information than if they had simply read it (Houston, 1991). During the process of gathering data using the inquiry approach the learner was required to isolate relevant variables and form a hypothesis about the example. Students reflected on whether or not the instructional content being presented was consistent with previous experiences or prior knowledge 
(basic physiology and anatomy, pharmacological concepts). Eighty percent of the students that responded to the learning impact study agreed that the learning object encouraged them to reflect on the material.

In order for learners to register information in their sensory systems, strategies consistent with cognitivist and constructivist approaches were applied. Learners were able to control the pace of the information and were directed to attend to specific information. Color was used to highlight the explanations of principles. The plotting of results in the blood time concentration curve was animated. As the curve was being drawn, a green arrow focused the learner's attention on the direction and magnitude of change in the graph. A three step memory model was suggested in order for the learners to transfer the information from short-term to long-term memory.

To promote deeper processing of the pharmacology principles the information was presented using the spreading activation model in which the students were able to see the relationship between the variables involved in drug administration and the effect this had on the patient. This approach was in direct contrast to the textbook where the principles are treated as individual concepts. Processing the network of related information provided the students with multiple pathways for assimilating or accommodating prior knowledge with new information and therefore makes it personally more meaningful. The opportunity to interpret their knowledge helped them to understand the context in which the different parameters operated.

A learning strategies guide for students was also included with the learning object for the following reasons. First, a set of effective strategies was provided to help them use the learning object to encode information so that it could be retrieved accurately. Students that receive direct instruction in using specific strategies perform better than students that are only told about the benefits of using certain approaches (Weinstein, 1978). This involves teaching learners the procedures of the strategy and when and where to apply it. The strategies and process outlined in the student guide were designed to help instructors providing this type of training.

Second, by explaining the steps involved in processing the information, the student was made aware of how these strategies could be used to improve learning. "Metacognition is the ability of a learner to be aware of his or her cognitive capabilities and use these capabilities to learn online" (Ally, 2004b p. 17). Nkanginieme (1997) asserted that, "making a clinical diagnosis is the pivotal cognitive activity of a practicing physician" (p. 1). However, this process has largely remained within the realm of the sub-conscious. By raising this type of activity to the level of consciousness (i.e. making them aware of the process by outlining them in the guide) one can be taught how to improve performance as well as acquire new knowledge.

An instructional strategies guide for teachers was also included with the learning object in order to identify some of the approaches that could be used in combination with the resource, thereby making it more reusable across a number of different contexts. For example, the instructor's guide suggests that, students may be asked to demonstrate their knowledge of pharmacokinetics by applying it to a case study, which has drug-related problems that occur with common disease states. Students would be engaged in thinking critically about the causes of the problems and could use the learning object to make decisions about the administration of drugs referenced in the case. The case could also be designed to evoke possible misconceptions about therapeutics that students may have developed.

\section{Evaluation Discussion}

The results from the 'think-aloud' session illustrated the value in conducting usability tests early in the design process. Issues taken for granted by the designers can easily be spotted by a fresh set of eyes viewing the learning object from the perspective of a student. Ideally it would have been better to carry out more of the sessions, but questions about ease of use and navigation were part 
of the student questionnaire. The responses for Usability of the Learning Objects subscale were in the Agree and Strongly Agree categories $80.0 \%$ of the time. Nielsen (2000) recommends using five participants for usability testing and claims that once you start collecting data from a single user, the insights gained increase by almost a third. In addition, more is learned from the first user than subsequent evaluators.

The evaluations of the quality of the learning object completed by faculty indicate that it will be a valuable resource for instruction. It is interesting to note that the content quality and the instructor/ student guides received the highest rating and reflects the amount of work that was done to select the appropriate strategies for the learning object. The high ratings for motivation reinforce the constructivist notion that activities, which engage the learner, are perceived as being more relevant and therefore more applicable for students. The 'very good' rating for reusability was somewhat surprising given the amount of modifications that were identified in order for it to be used in other contexts. The 'low score' by the one evaluator in the area of feedback/ adaptation may indicate that more direction is necessary for generating the graphs.

The quantitative measurement of the specified criteria using the five point scale provides a systematic framework to help faculty to assess the object in a more consistent manner. The clear explanations and examples of the different rating levels that were laid out in the guide that accompanies the LORI scoring sheet increases the possibility that the evaluation will be applied more consistently than if these items were not present. The amount of research and refinement of the LORI carried out by Vargo et al. (2003) adds to the credibility of this instrument.

Subjectivity cannot be completely removed from the process as each evaluator might selfconsciously assign different weights to some of the categories, but it does provide assurance to the future users of the object that it has passed a more rigorous inspection than peer reviews based on anecdotal comments. The requirement of justifying the score for each category forces the evaluator to reflect on the basis for their rating. It also provides the designer with useful information about where the perceived value lies. For example in rating the instructor and student guides, an evaluator made the following comment, "these were very clearly set out, and seem readily applicable. The philosophy of fully informing the student of the learning goals and strategies seems excellent!”

Using the convergent participant model for evaluation of learning objects developed by Nesbit et al. (2002) in combination with the LORI would be valuable for the evaluators as they would be able to learn more about the process of designing learning objects by being exposed to the rationales of the various assessors. It could increase the evaluators' awareness of the weak and strong points of the learning object. This would also increase the inter-rater reliability of the instrument (Vargo et al., 2003).

The 'learning impact study lite' served to reinforce the assumptions about the target audience, and the prior knowledge required by students in order to use the learning object. The results of the 'usability of technology' subscale (Agree and Strongly Agree 92.0\%) reflects the prevalent role that technology plays in student learning. The $75.7 \%$ and $77.5 \%$ (Agree and Strongly Agree) responses for the Learning Value subscale and the Value Added subscale suggests that the learning object will help students to better understand the therapeutic principles of drug administration. Most significantly, this reinforces the design decisions about the scope and sequence of the learning object. This also supports the rationale for developing a learning object that could convey the impact that a number of variables have on the overall effect of the drug and the achievement of optimum therapeutic effect. 


\section{Conclusion and Recommendations}

Making design decisions about the scope and sequence of a learning object merit a lot of consideration as they have significant implications for the quality of content development. These decisions should be informed by the theories of learning and cognition that are believed to enhance the process of acquiring and applying new knowledge. This position is in stark contrast to the one advocated by a number of authors who argue that the design of digital learning resources should be at the level of a common element in order to promote sharing with other institutions (Downes, 2000; Hamel \& Ryan-Jones, 2002; Longmire, 2000; Quinn \& Hobbs, 2000). The perceived affordances of this approach are based on the premise that learning objects designed at the level of a common element are more easily reused and re-purposed thereby reducing the production costs of these kinds of resources. Downes (2000) suggests that educators should adopt a 'Rapid Application Design' (RAD) methodology used by the software industry to develop high quality products quickly. This approach views online courses as collections of re-usable subroutines and applications. Designers can select and apply these pre-defined subroutines to the creation of new instructional materials.

The problem with promoting the re-purposing of learning objects is that it runs counter to instructional design best practices. In order to develop effective learning resources, the instructional designer needs to attend to the needs of the students for which the instructional challenge was identified. To reduce the pharmacology learning object to its most 'common elements' as advocated by Downes (2000) would have been to re-create what already existed in the textbook using another media. Is this really what we want? The reason for developing the learning object in the first place was the perception that the text book did not adequately represent or visualize the relationships that exist between therapeutic principles and the parameters relating to the physical and pharmacological properties of drugs. If the instructional designer attempted to take into account the multiple contexts in which the topic was being taught in order to design a learning object as a 'common element' and in order to promote its reuse, the process would have yielded dramatically different results. This would have meant de-contextualizing the learning object or stripping it of its inherent value. Wiley (2002) acknowledges this dilemma in what he referred to as the 'reusability paradox'.

"The purpose of learning objects and their reality seem to be at odds with one another. On the one hand, the smaller designers create their learning objects, the more reusable those objects will be. On the other hand, the smaller learning objects are, the more likely it is that only humans will be able to assemble them into meaningful instruction. From the traditional instruction point of view, the higher-level reusability of small objects does not scale well to large numbers of students (i.e., it requires teachers or instructional designers to intervene), meaning that the supposed economic advantage of reusable learning objects has evaporated".

Although, it is getting easier to retrieve materials (using technology like Rich Site Summary) and sharing resources (through repositories like CAREO, CLOE, MERLOT), teaching will require a great deal of thought and effort if it is to be effective. More time should be spent on exchanging best practices for designing and applying learning objects to instructional contexts than the content itself. The authors join Friesen (2004) in recommending that in-depth studies be undertaken to examine the "epistemological and ideological implications" of this approach.

The systematic evaluation of learning objects must become a valued practice, the importance of which will grow with the expansion of existing repositories. There is a need to assure educators that they are using resources that are highly rated and represent some added value to the learner (Boskic, 2003). Learning object repositories should not only house metadata about the pedagogical aspects of learning objects but should include the infrastructure to record summative evalua- 
tions, and information about how it is being used in instructional contexts. In addition, educating users of learning objects about accessibility and inter-operability standards would allow these criteria to be more widely adopted for evaluation purposes and increase the probability that they could be re-used by a greater number of people.

The combination of the Learning Object Review Instrument (LORI) created by Belfer et al. (2002) and the convergent participant model for evaluation of learning objects developed by Nesbit et al. (2002) represents a marked improvement over existing evaluation practices for learning objects, such as those undertaken by MERLOT. Organizations that are looking to promote learning object design and peer review as a scholarly activity should adopt this model to ensure that evaluations are rigorous, consistent and well recognized.

While using the learning object, Flash MX does have the ability to track user button selection and input from the mouse and keyboard. However, it was beyond the scope of this study. Future research may want to focus on the kind of information that could be obtained from this type of analysis. Recording the process that was used to generate a specific outcome would allow an instructor to provide valuable feedback to the student.

\section{Attributions}

Learning Object Design Team, Educational Computing, Faculty of Medicine, University of Toronto.

Lawrence Spero, PhD, is a Professor of Pharmacology and served as the subject matter expert. He developed the curriculum to support the learning object.

Meaghan Brierly, MScBMC, is an Instructional Media Designer with the Biomedical Communications division. This program specializes in developing multimedia applications for medical education. Meaghan used her skills in flash programming to design the interface and graphics that corresponded to the learning object.

Ju Ho Park, BASc, is the e-Based Instructional Developer and was responsible for programming the equation to calculate the effect of the drugs being administered and to create the database of drug information.

Ferdinand Krauss, BEd, is the Educational Instructional Designer (co-author of the study) who researched the cognitive theories of learning and the instructional strategies upon which the development of this learning object was based.

\section{References}

Abdelhamid, T. (1999). The multidimensional learning model: A novel cognitive psychology-based model for computer assisted instruction in order to improve learning in medical students. Med Educ Online, 1 (1), 1-8. Retrieved March 3, 2003, from http://www.msu.edu/ dsolomon/t0000007.pdf

Ally, M. (2004a). Designing effective learning objects for distance education. In R. McGreal (Ed.), Online Education Using Learning Objects (pp. 87-97). London: RoutledgeFalmer.

Ally, M. (2004b). Foundations of educational theory for online learning. In T. A. Anderson \& F. Elloumi (Eds). Theory and Practice of Online Learning (pp. 3-31). Athabasca University.

Bannan-Ritland, B., Dabbagh, N., \& Murphy, K. (2000). Learning object systems as constructivist learning environments: Related assumptions, theories and applications. In D. A. Wiley (Ed.), The instructional use of learning objects. Retrieved November 30, 2003, from http://reusability.org/read/chapters/bannan-ritland.doc

Belfer, K., Nesbit, J., \& Leacock, T. (2002) Learning object review instrument (LORI). Version 1.4 
Study of the Design and Evaluation of a Learning Object

Boskic, N. (2003). Faculty assessment of the quality and reusability of learning objects. Unpublished master's thesis, Athabasca University, AB.

Downes, S. (2000). Learning objects. Retrieved October 14, 2003, from http://www.atl.ualberta.ca/downes/naweb/Learning_Objects.doc

Duffy, T. M., \& Cunnigham, D. J. (1996). Constructivism: Implications for the design and delivery of instruction. In D. H. Jonassen (Ed.), Handbook of Educational Communications and Technology (pp. 170-198). New York: Simon \& Schuster Macmillan.

Friesen, N. (2004). Three objections to learning objects. Retrieved January 14, 2004, from http://phenom.educ.ualberta.ca/ nfriesen/

Hamel, C. J., \& Ryan-Jones, D. (2002). Designing instruction with learning objects. International Journal of Educational Technology, 3 (1). Retrieved January 15, 2004, from http://www.ao.uiuc.edu/ijet/v3n1/hamel/index.html

Houston, J. P. (1991). Fundamentals of learning and memory (4th ed.). Florida: Harcourt Brace Jovanovich.

Hung, D. (2001). Theories of learning and computer-mediated instructional technologies. Education Media International, 38 (4), 281-287.

Leeder, D. (2003). Learning object instructor and student surveys. Universities' Collaboration in eLearning. Retrieved November 17, 2003, from http://www.ucel.ac.uk/resources/dev_pack.html 11/2003

Longmire, W. (2000, March). A primer on learning objects. ASTD Learning Circuits, Retrieved November 23, 2003, from http://www.learningcircuits.org/2000/mar2000/Longmire.htm

Melmon, K. L., \& Morrelli, H. F. (1972). Clinical pharmacology: Basic principles in therapeutics. Toronto, ON: Collier-Macmillan Publishing.

Merrill, M. D. (1992). Constructivism and instructional design. In T. M. Duffy, \& D. H. Jonassen (Eds.), Constructivism and the technology of instruction: A conversation (pp. 99-115). Hillsdale, NJ: Lawrence Erlbaum Associates.

Nesbit, J., Belfer, K., \& Vargo, J. (2002). A convergent participant model for evaluation of learning objects. Canadian Journal of Learning and Technology, 28 (3). Retrieved August 3, 2003, from http://www.cjlt.ca/content/vol28.3/nesbit_etal.html

Nielson, J. (2000). Why you only need to test with 5 users. Retrieved December 17, 2003, from http://www.useit.com/alertbox.20000319.html

Nkanginieme, K. E. O. (1997). Clinical diagnosis as a dynamic cognitive process: Application of Bloom’s taxonomy for educational objectives in the cognitive domain. Medical Education Online, 2 (1), 1-6. Retrieved March 5, 2003, http://www.msu.edu/ dsolomon/f0000007.pdf

Nyhof-Young, J., Walsh, L., \& Stewart, P. (2002, June). Let's ask the users! Development and implementation of an evaluation strategy for multimedia teaching software. Proceedings of the 2003 International Slice of Life conference, University of Toronto, ON.

Patton, M. Q. (1997). Utilization-focused evaluation. (3rd ed.) Thousand Oaks, CA: Sage.

Quinn, C., \& Hobbs, S. (2000). Learning objects and instructional components. Educational Technology and Society, 3 (2). Retrieved August 3, 2003, from http://ifets.ieee.org/periodical/vol_2_2000/discuss_summary 0200.html

Rose, D. (2003). CLOE learning impact studies lite: Evaluating learning objects in nine Ontario university courses. Report presented to the Office of Learning Technologies Human Resources Development Canada, Retrieved August 21, 2003, from http://lt3.uwaterloo.ca/CLOE/MERLOTConferencePaper10.doc

Skinner, B.F. (1974) About behaviourism. London, UK: Penguin.

Smith, P.L., \& Ragan, T.J. (1999). Instructional design. (2nd ed.). Toronto, ON: John Wiley \& Sons. 
Shaw, S. (2002, February). Designing online facilities that really leverage learning. Proceeding of the Knowledge Media Design Institute [Interactive Webcast], University of Toronto, ON, Retrieved August 24, 2003, from http://epresence.kmdi.toronto.edu/archived.asp

Stufflebeam, D. L. (1971). The relevance of the CIPP evaluation model for educational accountability. Journal of Research and Development in Education, 5 (1), 19-25.

Vargo, J., Nesbit, J., Belfer, K., \& Archambault, A. (2003). Learning object evaluation: Computer mediated collaboration and inter-rater reliability. International Journal of Computers and Applications, 25 (3), $1-8$.

Weinstein, C. E. (1978). Elaboration skills as a learning strategy. In H. F. O’Neil (Ed.), Learning Strategies (pp. 31-55). New York: Academic Press.

Wiley, D. A. (2000). Learning object design and sequencing theory. Unpublished Doctoral Dissertation, Brigham Young University, Provo, UT, Retrieved November 2, 2003, from http://davidwiley.com/papers/dissertation/dissertation.pdf

Wiley, D.A. (2002). The reusability paradox. Retrieved November 2, 2003, from http://rclt.usu.edu/whitepapers/paradox.html

Williams, D. D. (2000). Evaluation of learning objects and instruction using learning objects. In D. A. Wiley (Ed.), The instructional use of learning objects. Retrieved November 30, 2003, from http://reusability.org/read/chapters/williams.doc

\section{Appendix A: Instructor Ratings for Pharmacology Learning Object}

\begin{tabular}{|c|c|c|c|c|c|c|}
\hline LoW & & & & & & \\
\hline $\begin{array}{l}\text { 1. Content Quality: Veracity, accuracy, bal- } \\
\text { anced presentation of ideas, and appropriate } \\
\text { level of detail }\end{array}$ & 1 & 2 & 3 & 4 & 5 & NA \\
\hline \multicolumn{7}{|l|}{ Rationale: } \\
\hline \multicolumn{7}{|l|}{$\begin{array}{l}\text { E1 While I am not a pharmacologist and so } \\
\text { do not believe I should comment on the accu- } \\
\text { racy or veracity (so have bolded NA as well } \\
\text { as making a numerical selection), I believe } \\
\text { that the overall balance of the LO and the } \\
\text { level of detail seem excellent. }\end{array}$} \\
\hline E2 Works as an adjunct to the text. & & & & & $\mathrm{X}$ & \\
\hline
\end{tabular}




\section{Learning Goal Alignment: Alignment among learning goals, activities, assessments, and learner characteristics \\ Rationale: \\ E1 The LO seems to strongly reinforce the therapeutic principles presented, and the rela- tionships between concepts. It allows a high level of learner interaction.}

\begin{tabular}{|l|l|l|l|l|l|l|}
\hline 1 & 2 & 3 & 4 & 5 & & NA \\
\hline
\end{tabular}
$\mathrm{X}$

E2

$\mathrm{X}$

3. Feedback and Adaptation: Adaptive content or feedback driven by differential learner input or learner modeling

Rationale:

E1 The LO does - as is stated in the description - expect a certain level of background from the students - and so may be very chal$\mathrm{X}$ lenging for students just undertaking the study of pharmacology.

E2 After plotted curves several times, it's impossible to go back and view the previous

\begin{tabular}{|l|l|l|l|l|l|l|}
\hline 1 & 2 & 3 & 4 & 5 & & NA \\
\hline
\end{tabular}
curves.

4. Motivation: Ability to motivate, and stimulate the interest or curiosity of, an identified population of learners

Rationale:

E1 The content seems highly relevant and stimulating for students - especially those in the health sciences - the clinical applicability $\mathrm{X}$ seems readily apparent.

E2 Able to modify the variables.

$\mathrm{X}$

5. Presentation Design: Design of visual and auditory information for enhanced learning and efficient mental processing

\begin{tabular}{|l|l|l|l|l|l|l|}
\hline 1 & 2 & 3 & 4 & 5 & & NA \\
\hline
\end{tabular}

Rationale:

E1 Overall the design seems very effective. One minor comment - the text with patient variables at the bottom could be slightly lar$\mathrm{X}$ ger.

E2 Clear visual information. It would be better if it had auditory information. 


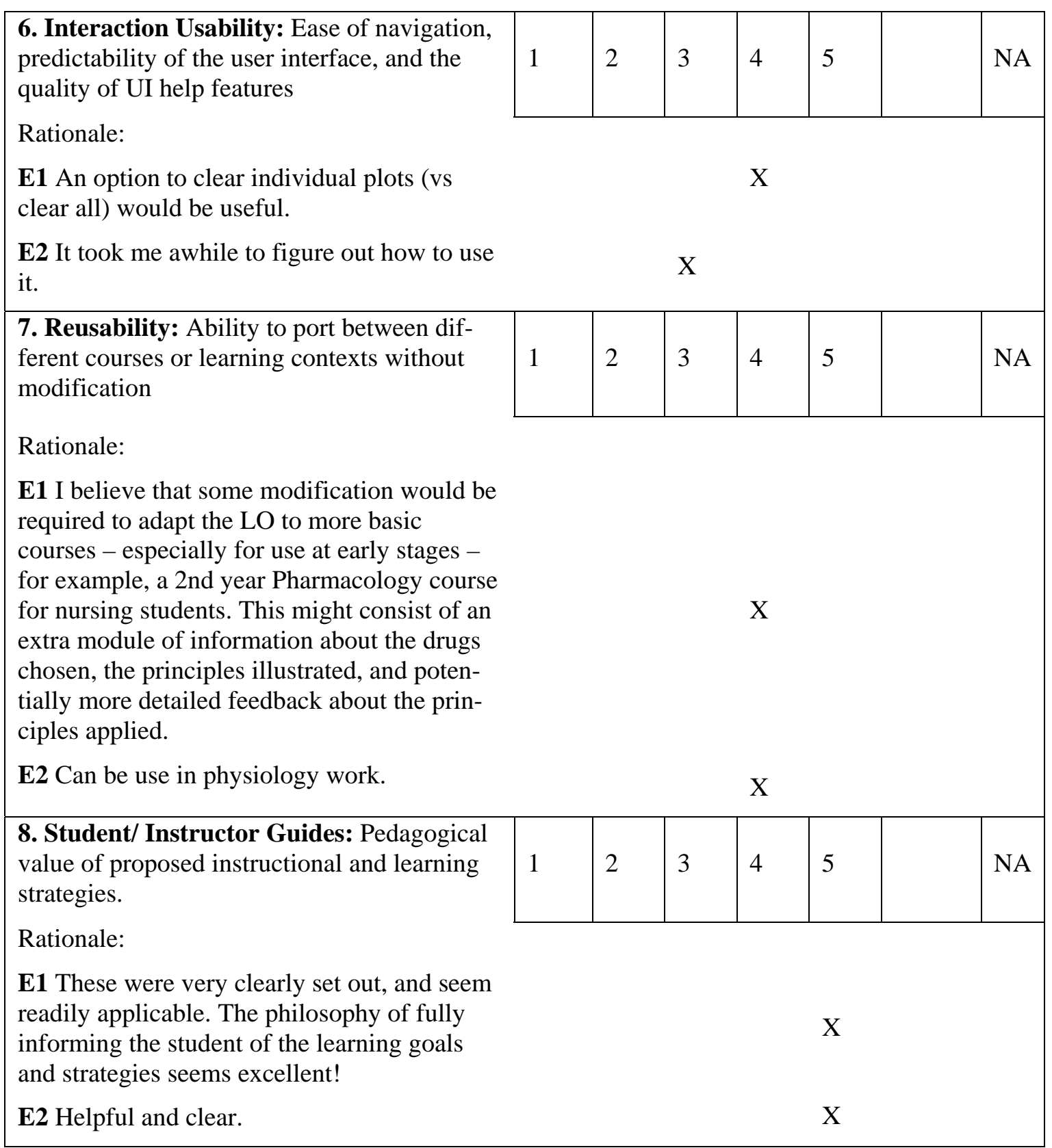




\section{Appendix B. Student Questionnaire Results on University of Toronto's Pharmacology Learning Object}

Percentage of possible responses assigned to each category, within four subscales. (Ten students responded to the questionnaire.)

\begin{tabular}{|l|l|l|l|l|l|l|}
\hline Subscale & $\begin{array}{c}\% \\
\text { Strongly } \\
\text { Agree }\end{array}$ & $\begin{array}{c}\% \\
\text { Agree }\end{array}$ & $\begin{array}{c}\% \\
\text { Neutral }\end{array}$ & $\begin{array}{c}\% \\
\text { Disagree }\end{array}$ & $\begin{array}{c}\% \\
\text { Strongly } \\
\text { Disagree }\end{array}$ & $\begin{array}{c}\% \\
\text { N/A }\end{array}$ \\
\hline $\begin{array}{l}\text { 1. Learning Value } \\
(\mathrm{n}=70)\end{array}$ & 35.7 & 40 & 18.6 & 1.4 & 1.4 & 1.4 \\
\hline $\begin{array}{l}2 . \text { Value Added by LOs } \\
(\mathrm{n}=80)\end{array}$ & 47.5 & 30 & 13.8 & 5.7 & 1.3 & 2.5 \\
\hline $\begin{array}{l}\text { 3. Usability of LOs } \\
(\mathrm{n}=40)\end{array}$ & 35.0 & 45.0 & 5.0 & 10.0 & 0.0 & 5.0 \\
\hline $\begin{array}{l}4 . \text { Usability of Tech } \\
(\mathrm{n}=50)\end{array}$ & 66.0 & 26.0 & 4.0 & 0.0 & 0.0 & 4.0 \\
\hline
\end{tabular}

Note: $\mathrm{n}=$ the number of possible times a response category was selected for all items in a subscale.

\section{Biographies}

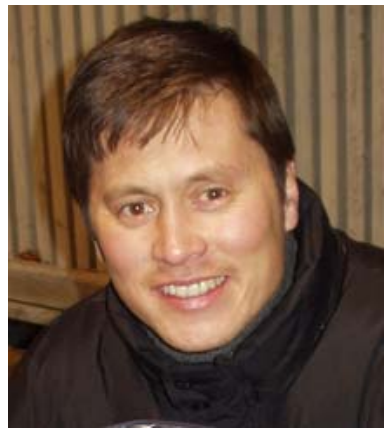

Ferdinand Krauss is an instructional designer at the Resource Centre for Academic Technology and the Educational Computing Division of the Faculty of Medicine, University of Toronto, Canada. He develops and delivers an online faculty development certificate program about web-based teaching strategies. Ferdinand completed his Bachelor of Education at the University of Toronto in 1995 and is currently working towards a Master in Distance Education at Athabasca University in Alberta. Ferdinand's research interests include learning theory and cognition, instructional technology design, faculty development and e-learning delivery models.

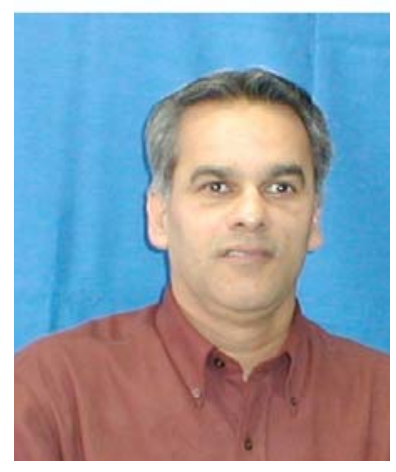

Mohamed Ally is an Associate Professor at Athabasca University. Dr. Ally has been involved in distance education and online learning for many years and has conducted research in the areas of providing student support in distance education, learning objects integration in online learning, mobile learning, project management, and the use of technology in delivery. 